\title{
Relationship Between Hind Limb Lameness and Radiographic Signs of Bone Spavin in Icelandic Horses in Sweden
}

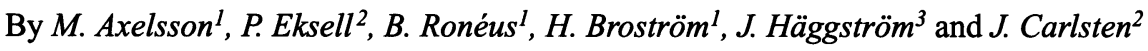 \\ ${ }^{1}$ Department of Large Animal Clinical Sciences, ${ }^{2}$ Clinical Radiology, and ${ }^{3}$ Animal Physiology, Faculty of \\ Veterinary Medicine, Swedish University of Agricultural Sciences, Uppsala, Sweden.
}

\begin{abstract}
Axelsson M, Eksell P, Ronéus B, Broström H, Häggström J, Carlsten J: Relationship between hind limb lameness and radiographic signs of bone spavin in icelandic horses in Sweden. Acta vet. scand. 1998, 39, 349-357. - A field study was designed to estimate the prevalence of hind limb lameness in a population of Icelandic horses in Sweden. All available Icelandic horses at 11 different farms within $150 \mathrm{~km}$ from Uppsala were examined once during a study period of 13 months. The relationship between hind limb lameness and radiographic signs of bone spavin (RSBS) was investigated. The rate of agreement between the outcome after palpation, motion evaluation and flexion test and radiographic examination was established.

A total of 379 horses including 238 geldings, 125 mares and 16 stallions, with mean age 8.1 years (range 1-19 years) were examined by palpation of the medial aspect of the tarsal joints, motion evaluation and flexion test of the hind limbs. One dorsolateral-plantaromedial oblique radiographic view was recorded from each tarsus.

Palpable abnormalities were found in 118 horses $(31 \%)$. Forty-three horses $(12 \%)$ were lame at presentation, 94 horses (25\%) were positive on flexion test and 88 horses $(23 \%)$ had RSBS. There was a significant relationship between palpable abnormalities, lameness, positive flexion test and RSBS. The proportion of joints with RSBS increased with increasing severity of physical findings. The proportion of lame limbs increased with increasing radiographic changes. The presence of palpable findings or positive flexion test was not influenced by the grading of radiographic changes. Using palpation, motion evaluation, and flexion test $75 \%$ of the horses with RSBS were identified. The rate of agreement between the clinical examination and the radiographic examination was $73 \%$.
\end{abstract}

equine; degenerative joint disease; radiology; tarsus.

\section{Introduction}

Over the past years the number of Icelandic horses has increased considerably in Sweden. In 1980 the Swedish Icelandic Horse Registry held 300 horses and in December 1997 the number were 8200 horses (Lindberg 1998). This increasing popularity relates to several attractive qualities of the breed. It is well known for its gaits, which besides walk, trot and gallop, include pace and toelt, for a lively temperament and strong but supple character (Hugason 1994). Thus, an increasing number of horses are being presented to equine practitioners. Often, the problem relates to the locomotor system and is described as unwillingness to 
move or uneven movement at different gaits, especially in the toelt. Sometimes the horse has a tendency to break the gait into a gallop that is hard to control. Complaints of lameness are less common. A thorough clinical examination, including inspection, palpation, motion evaluation and flexion test (Stashak et al. 1987, Todhunter 1992) of these horses often reveals hind limb lameness associated with radiographic signs of bone spavin (RSBS). However, the clinical importance of RSBS is unclear since it is sometimes found in horses free from clinical signs of lameness (Gabel 1980).

Bone spavin is a common cause of lameness accounting for $9 \%$ of all cases of lameness (Bergsten 1983), and for $27 \%$ of cases with hind limb lameness (Gabel 1983) . Bone spavin is defined as a degenerative joint disease affecting the intertarsal and tarsometatarsal joints (Barneveld 1983). The centrodistal joint (CD) and the tarsometatarsal joint (TMT) are most commonly affected, while pathological changes are seldom found in the proximal intertarsal joint (PIT) (Barneveld 1983). RSBS are essential for definite diagnosis and include periosteal formation of new bone, subchondral bone lysis, subchondral sclerosis and narrowing or loss of joint spaces (O' Brien 1974, Butler et al. 1993). The aetiology of bone spavin is considered multifactorial, including genetic factors (Barneveld 1983, Gabel 1983, Winter et al. 1996), developmental abnormalities (Barneveld 1983, Gabel 1983, Hartung et al. 1983, Stashak et al. 1987, Watrous et al. 1991) and non-genetic factors, such as type of work, workload (Rooney 1968, Gabel 1980) and trauma (Rooney 1968, Stashak et al. 1987).

This study was initiated in order to estimate the prevalence of hind limb lameness in a population of Icelandic horses in Sweden and to investigate the relationship between hind limb lameness and RSBS.

\section{Materials and methods}

Horses

Farms within $150 \mathrm{~km}$ of Uppsala and holding a minimum of 20 Icelandic horses, all of which could be examined and included in the study, were selected. A total of 379 horses: 238 geldings, 125 mares and 16 stallions, mean age 8.1 years (range 1-19 years) at 11 farms were examined. This was done on 8 different occasions during a time period of 13 months. The sample size corresponded to approximately $6.2 \%$ of the Icelandic Horse population registered in Sweden at the time of the investigation (Lindberg 1997).

\section{Physical examination/tests}

Each horse was examined and data recorded according to a standard protocol by 1 of 3 equine clinicians. The examination consisted of palpation, motion evaluation, and flexion test. These 3 methods of examination are hereafter referred to as "tests".

Palpation. The medial aspect of the intertarsal joints and tarsometatarsal joints was palpated. Hard tissue swelling, indistinct margins separating the central tarsal bone, third tarsal bone and third metatarsal bone were recorded and graded as not present, mild, moderate or severe.

Motion examination. Lameness was evaluated while trotting the horse in hand on a firm surface 25-30 meters straight away from the examiner and back. In doubtful cases the horse was assigned as free from lameness.

Flexion test. Flexion test was carried out by maximal flexion of each tarsus for one min before trotting. Lameness during motion evaluation and lameness after flexion test were graded and recorded as not present, mild, moderate, severe, very severe or non weight bearing (0-5) according to Asheim et. al. (1976). The flexion test was regarded as positive when there was an increase in degree of lameness. 


\section{Radiographic examination}

A portable radiographic unit (Medinos 100/80 Hermansson AB Malmö Sweden) and developing machine were used (Gevamatic AGFAGEVAERT München Germany). A standard dorsolateral-plantaromedial oblique view was recorded from each tarsus centred on the intertarsal and tarsometatarsal joints. Care was taken that the exposure settings and the latitude film-screen combination used produced optimal grey scale radiographs for evaluation of subtle bony details. Radiographic signs of degenerative joint disease in one or more of the PIT, the CD and the TMT was used as diagnostic criteria for bone spavin (Barneveld 1983, Butler et al. 1993). Radiographs were coded and radiographic findings were graded (mild, moderate and severe), after consensus, by 2 radiologists without knowledge of the clinical status of the horses. To validate the method tarsi $(n=193)$ from 98 different Icelandic horses were radiographed in 4 projections (dorsoplantar, lateromedial, dorsolateral-plantaromedial oblique, plantarolateral- dorsomedial oblique) and films were evaluated according to the same criteria. It was found that the dorsolateral-plantaromedial oblique projection had a sensitivity of $93 \%$ and a specificity of $84 \%$ in detecting RSBS compared with reading all 4 projections of the same limb together.

\section{Data Analysis}

Statistical differences among groups of horses with categorical data, e.g. test positive vs. RSBS positive, were determined by the $\chi^{2}$-test. In cases of ordered classes, the linearity of test score groups vs. RSBS score groups was tested by the Chi Square trend test (Bland 1991). The association between clinical findings and RSBS with age was tested for by logistic regression. Age was modelled both as a continuos variable and as a grouped variable. The level of significance was chosen as $\mathrm{p}<0.05$.
Rate of agreement was defined as the sum of the test positive and RSBS positive limbs and the test negative and RSBS negative limbs divided by all investigated limbs. Rate of disagreement was defined as the sum of the test negative limbs and RSBS negative limbs divided by all investigated limbs. The rates of agreement and disagreement were calculated step-wise for the presence of palpable abnormalities, lameness, and positive flexion test to evaluate these variables as clinical tests. The rates were first calculated for palpation only, and then the test was extended also to include motion evaluation and lastly, the test was extended further to include the flexion test. A horse was considered test positive if one or more of the included variables were positive. Data analysis was performed with a computerised statistical program (SAS Institute Inc. 1995).

\section{Results}

Prevalence of palpable findings, lameness, and lameness after flexion test

Out of the 379 examined horses, $31 \%(n=118)$ had palpable abnormalities over the medial aspect of the tarsal joints. Palpable abnormalities were more prevalent in the right limb than in the left limb $(p=0.045)$ and more were scored as moderate in right limbs than in left limbs (Table 1). Out of the 379 examined horses $12 \%$ $(n=43)$ were lame (Fig. 1). Positive flexion test was more frequently found in right hind limbs than in left hind limbs $(p=0.031)$ (Table 1). Lameness was bilateral in 3 horses. Positive flexion test was found in $25 \%(n=94)$ of the 379 horses. Positive flexion test was more frequent $(p=0.007)$ and more severe in right hind limbs (Table 1).

\section{Localisation of RSBS}

RSBS was found in $23 \%(n=88)$ of the horses, with a total of 135 limbs affected, 63 left and 72 right limbs (Table 2). Of the horses with RSBS both limbs were affected in $53 \%(n=47)$ and 
Table 1. Distribution of clinical examination scores for palpation, motion evaluation and flexion test in left and in right limbs in 379 horses.

\begin{tabular}{|c|c|c|}
\hline & Left hind & Right hind \\
\hline Palpalation score & \multicolumn{2}{|c|}{ Number of palpated limbs } \\
\hline Normal & 305 & 281 \\
\hline Mild & 62 & 73 \\
\hline Moderate & 9 & 22 \\
\hline Severe & 3 & 3 \\
\hline Total test positive & 74 & 98 \\
\hline Lameness score & \multicolumn{2}{|c|}{ Number limbs, motion evaluation } \\
\hline Normal & 363 & 349 \\
\hline Mild & 16 & 22 \\
\hline Moderate & 0 & 7 \\
\hline Severe & 0 & 1 \\
\hline Very severe & 0 & 0 \\
\hline Not weight bearing & 0 & 0 \\
\hline Total test positive & 16 & 30 \\
\hline Flexion test score & \multicolumn{2}{|c|}{ Number of limbs, flexion test } \\
\hline Normal & 336 & 311 \\
\hline Mild & 32 & 43 \\
\hline Moderate & 9 & 19 \\
\hline Severe & 2 & 6 \\
\hline Very severe & 0 & 0 \\
\hline Not weight bearing & 0 & 0 \\
\hline Total test positive & 43 & 68 \\
\hline
\end{tabular}

the remaining $47 \%(n=41)$ had one limb affected. Most limbs (97\%) were affected in 1 or 2 joints with CD and TMT most commonly involved. Osteoarthritis in PIT was found in $8 \%$ of the limbs with RSBS (Table 2).

\section{Radiographic score}

In the TMT joint the degree of RSBS was almost evenly distributed between the scores mild, moderate and severe, and radiographic signs of severe lesions were most prevalent in this joint. Less severe lesions were found in the CD joint. All limbs with changes in the PIT were scored as mild, with the exception of one case scored as moderate (Fig. 2).
Relationship between the results from the clinical examination and radiographic score

Overall, RSBS was found in $45 \%(n=53)$ of the horses with palpable abnormalities, in 53\% $(\mathrm{n}=23)$ of those presented with lameness, and in $44 \%(n=41)$ of the horses that were positive after flexion test (Fig. 1). The relationship between the clinical signs and RSBS was not significantly influenced by age. Analysis of single limbs showed that the proportion of limbs with RSBS free from palpable abnormalities was $12 \%(n=68)$, whereas the proportion of limbs with RSBS in limbs affected with palpable abnormalities was higher $(p<0.0001)$, at $39 \%$ $(n=67)$. In the group of horses with palpable 


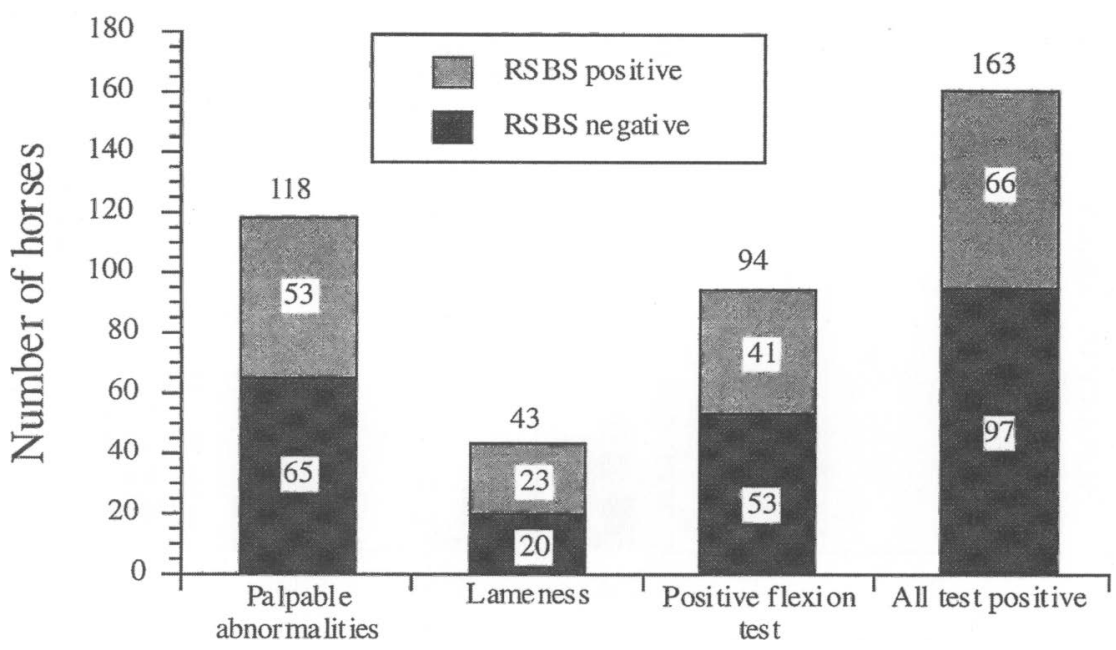

Figure 1. Clinical findings in 379 examined Icelandic horses. Each column represents number of horses with positive result for each test. The top section of the column shows the number of horses with agreement between physical examination and radiographic signs of bone spavin (RSBS).

abnormalities, the proportion of limbs with RSBS increased with increasing severity of palpation score (Fig. 3) $(\mathrm{p}<0.01)$, but severity of RSBS was not correlated with the presence of palpable abnormalities per se, in horses with RSBS. Lameness was found in $16 \%(n=111)$ of the limbs free from RSBS and in 53\% $(n=24)$ of the limbs with RSBS $(p<0.0001)$.

Table 2. Distribution of radiographic signs of bone spavin (RSBS) in one standard dorsolateral-plantaromedial oblique view, in left and right limbs by number of affected joints and percentage joint distribution in 88 Icelandic horses $(\mathrm{PIT}=$ proximal intertarsal joint, $\mathrm{CD}=$ centerodistal joint, $\mathrm{TMT}=$ tarsometatarsal joint $)$.

\begin{tabular}{|c|c|c|c|c|}
\hline \multirow{2}{*}{$\begin{array}{l}\text { No. of affected } \\
\text { joints: }\end{array}$} & \multicolumn{2}{|c|}{ Left tarsus } & \multicolumn{2}{|c|}{ Right tarsus } \\
\hline & $\begin{array}{c}\text { Number of } \\
\text { limbs }\end{array}$ & $\begin{array}{c}\text { Distribution } \\
\text { between joints }\end{array}$ & $\begin{array}{c}\text { Number of } \\
\text { limbs }\end{array}$ & $\begin{array}{c}\text { Distribution } \\
\text { between joints }\end{array}$ \\
\hline One joint & 35 & $\begin{array}{c}{ }^{1} \text { PIT } 0 \% \\
{ }^{2} \text { CD 57\% } \\
{ }^{3} \text { TMT 43\% }\end{array}$ & 38 & $\begin{array}{c}\text { PIT 3\% } \\
\text { CD 58\% } \\
\text { TMT 39\% }\end{array}$ \\
\hline Two joints & 27 & $\begin{array}{c}\text { PIT\&CD 7\% } \\
\text { PIT\&TMT 2\% } \\
\text { CD\&TMT 91\% }\end{array}$ & 31 & $\begin{array}{c}\text { PIT\&CD 7\% } \\
\text { PIT\&TMT 2\% } \\
\text { CD\&TMT 91\% }\end{array}$ \\
\hline Three joints & 1 & & 3 & \\
\hline Total & 63 & & 72 & \\
\hline
\end{tabular}

${ }^{1}$ PIT = proximal intertarsal joint.

${ }^{2} \mathrm{CD}=$ centerodistal joint.

3 TMT $=$ tarsometatarsal joint. 


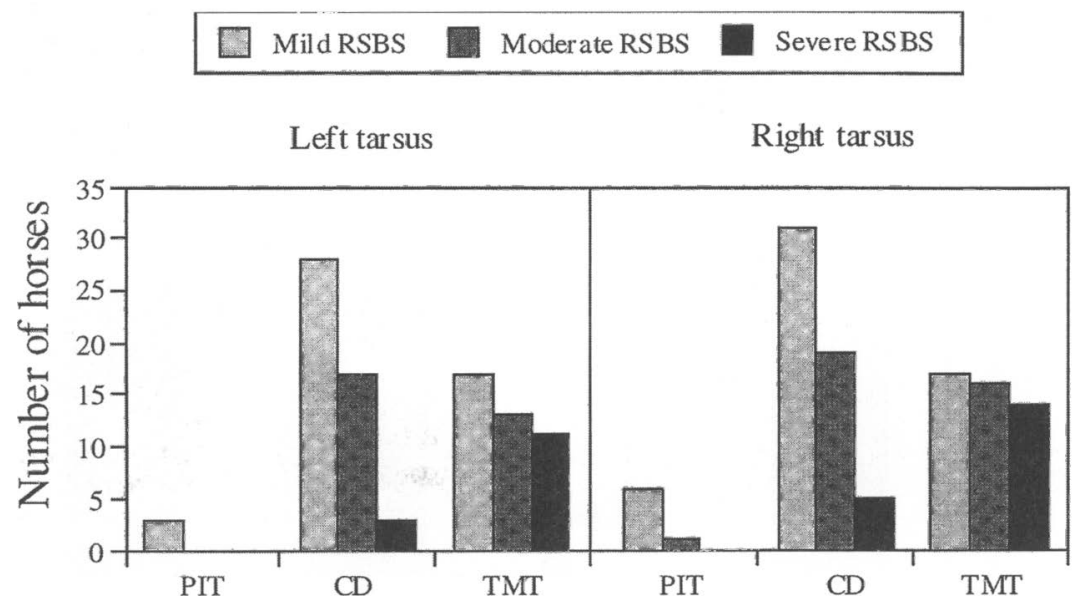

Figure 2. Distribution and grading of radiographic signs of bone spavin (RSBS) in one standard dorsolateralplantaromedial oblique view by joint localisation (PIT $=$ proximal intertarsal joint, $\mathrm{CD}=$ centrodistal joint, TMT $=$ tarsometatarsal joint $)$ in 88 Icelandic horses.

The proportion of joints with RSBS increased with increasing severity of lameness $(p<0.001)$ (Fig. 3), likewise the proportion of lame limbs increased with increasing RSBS score (4\% limbs lame in group 0 for RSBS, $9 \%$ in the group scored $1,17 \%$ in the group scored 2 and $28 \%$ in the group scored 3) $\mathrm{p}<0.001$. Of the limbs with negative flexion test $14 \%(n=91)$ had RSBS, whereas $40 \%(n=44)$ of the limbs positive for flexion test had RSBS $(\mathrm{p}<0.0001)$. after flexion test $(\mathrm{p}<0.05)$ (Fig. 3): The proportion of RSBS among horses positive to flexion test was $34 \%$ of limbs with mild lameness after flexion test, $39 \%$ of those with moderate lameness after flexion test and $88 \%$ of those with severe lameness (Fig. 3). The proportion of limbs positive after flexion test was not significantly influenced by the severity of RSBS (13\% limbs positive after flexion test in the group scored 0 for RSBS, $36 \%$ in the group scored $1,38 \%$ in the group scored 2 and $36 \%$ in the group scored 3 for RSBS) ( $>00.05$ ).

The rate of agreement between the clinical tests and the radiographic examination was between
$73 \%$ and $77 \%$ : It was $77 \%$ between palpation and radiographic examination alone. Adding motion examination to the clinical test did not change the rate of agreement while the rate of agreement dropped to $73 \%$ after flexion test also was included.

\section{Discussion}

Epidemiological studies of bone spavin in different horse populations indicate that the prevalence of the disease varies between different breeds. Data from an animal insurance company show that the number of claims for bone spavin among the insured population of Swedish Warmblods, ponies and mixed breeds range between $0.01 \%$ and $0.02 \%$ (Bergsten 1983) while the claims for bone spavin in the insured population of Icelandic horses were $1.2 \%$ (Odenhall 1996). A frequency of $1.2 \%$ of the disease was found in horses admitted at the Ohio University Veterinary Hospital (Gabel. 1983), representing a mixture of breeds. In contrast, the prevalens of RSBS among Icelandic 


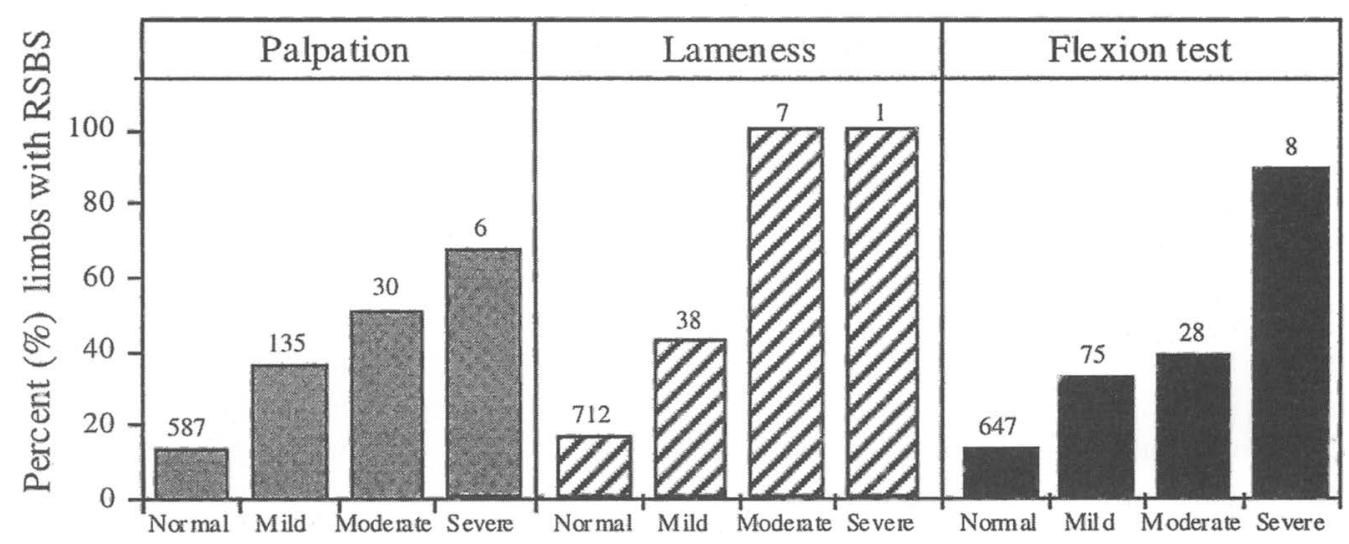

Figure 3. Clinical findings in 758 investigated limbs (379 Icelandic horses) according to palpation, motion evaluation and flexion test. Limbs are grouped according to severity of clinical findings under categories, normal, mild, moderate or severe. Each column thus shows the proportion of limbs with radiographic signs of bone spavin (RSBS) in that particular result group. The figures on top of columns represent the total number of limbs in each result group.

horses in this study was $23 \%$. This indicates a predisposition to the disease in Icelandic horses. Several factors, such as age and level of work, must be taken into consideration before any direct comparisons can be made between the studies. Sample suitability as well as prevalence and risk factors of RSBS in Icelandic horses have been discussed elsewhere (Eksell et al. 1998).

Clinical abnormalities were more prevalent in right hind limbs. The clinical abnormalities were also more severe in these limbs. This difference may be the result of asymmetrical training or may have been caused by a natural lateral preference. Repetitive training of Standardbred trotters in one direction around a track may provoke asymmetrical lameness due to joint lesions (Dalin et al. 1973). However, the Icelandic horse is not subjected to this type of repetitive training. In training and competition, Icelandic horses are ridden both clockwise and counter clockwise in left and in right leads, without preference for one or the other. Sidedness or lateral preference is well known among horsemen. Indeed, asymmetries in the locomotion pattern have been demonstrated by high speed cinematography, which revealed a preference for left sidedness in healthy Standardbred trotters (Drevemo et al. 1980, Drevemo et al. 1987). A lateral preference is considered to be a naturally occurring character of the horse but may be altered in response to type of training applied (Drevemo et al. 1987). Asymmetries in the locomotion pattern are believed to result in increased strain with ensuing pathological changes in the locomotor system (Rooney 1968). Accordingly, the reason for different prevalence and severity of palpable abnormalities, lameness and lameness after flexion test in right vs. left leg that was found in this study is more likely to be an effect of sidedness rather than an effect of training and riding technique. In this study, $45 \%$ of the Icelandic horses with palpable abnormalities were found to have RSBS, and $87 \%$ of the horses without palpable changes were correctly identified as free from RSBS. In some horses the radiographic changes were located strictly along the joint 
spaces and subchondral bone, without new bone formation along the medial aspect of the joint. This may be the reason why a number of horses with RSBS, even cases with moderate or severe RSBS, were not detected by palpation. On the other hand there are reasons to believe that palpation might be a good method in detecting early cases of bone spavin in which only through a more thorough radiographic examination, RSBS is identified. Among the horses with hind limb lameness 53\% had RSBS, whereas $80 \%$ of those without lameness were free from RSBS. There are at least 3 reasons why horses with RSBS were not identified by motion evaluation in this study. Most horses were presented in trot during motion examination and flexion test. Due to different gait preferences and the fact that the examined horses had not been trained to trot with halter, some horses were presented in pace, toelt or in a mixture of gaits rather than in trot, which made the motion evaluation difficult. Some horses were bilaterally affected, which also may have caused difficulties for the examiner to detect lameness. Examination of disturbances in locomotion pattern during trotting in a small circle could have revealed lameness in some of the bilaterally affected horses. The third reason is that some horses with RSBS were simply not lame. In horses with positive flexion test $45 \%$ were affected with bone spavin, whereas in the horses with no reaction to the flexion test $86 \%$ were free from RSBS. This finding also supports that, in some instances, RSBS may be present without eliciting lameness. To our knowledge it is not known whether these horses will stay sound or will develop lameness over a period of time. It also remains to be investigated whether horses reacting to flexion test but with no RSBS will develop RSBS over time.

When using the 3 tests: palpation, motion evaluation and flexion test, $40 \%(n=66)$ of the 163 horses that were test positive for one or more of these tests, were RSBS positive. Certainly, there are reasons for hind limb lameness and positive flexion test in the hind quarters other than bone spavin. Nevertheless these findings may also suggest that, when using a single dorsolateral-plantaromedial oblique view, the occurrence of bone spavin is underestimated. A more thorough radiographic examination with several projections would have been more sensitive, and cases of less severe bone spavin among the $61 \%$ with one or more positive test results but negative for RSBS might have been detected and thereby also increase the rate of agreement between the clinical and radiographic appearance.

\section{Acknowledgements}

Supported by Försäkringsbolaget Agria (Agria Insurance), Stockholm, Sweden.

The authors thank Professor Peter Lord for linguistic advice and constructive criticism, and all technicians for excellent assistance.

\section{References}

Barneveld A: Spavin in the horse. University of Utrecht, Utrecht, The Netherlands. 1983, PhD thesis.

Bergsten G: Sjukdomsfrekvenser i rörelseorganen hos ett material försäkrade hästar 1973-1981 (Frequency of diseases of the locomotor system among insured horses), Svensk Vet. Tidn. 1983, 35, Suppl. 3, 14-20.

Bland M: An Introduction to Medical Statistics. Oxford, Oxford Medical Publications. 1991.

Butler JA, Colles CM, Dyson SJ, Kold SE, Poulos $P W$ : Clinical Radiology of the Horse. Blackwell Scientific Publications, Oxford. 1993, 211-245.

Dalin G, Drevemo S, Fredricson I Jonsson, K, Nilsson $G$ : Ergonomic aspects of lokomotor asymmetry in Standardbred horses trotting through turns. Acta. vet. scand. 1973, Suppl. 44, 111-139.

Drevemo S, Fredricson I, Dalin G, Björne K: Equine locomotion: 2 . The analysis of coordination between limbs of Standardbreds. Equine Vet. J. $1980,12,66-70$. 
Drevemo S, Fredricson I, Hjerten G, McMiken D: Early development of gait asymmetries in trotting Standardbred colts. Equine Vet. J. 1987, 19, 189191.

Eksell P, Axelsson M, Häggström J, Broström H, Ronéus B, Carlsten J: Prevalence and riskfactors of radiographic signs of bone spavin in Icelandic horses in Sweden: A radiographic field study. Acta vet. scand. 1998, 39, 339-348.

Gabel $A$ A: Lameness caused by inflammation in the distal hock. Vet Clin North Am Large Anim Pract. 1980, 2, 101-24.

Gabel $A$ A: Prevention, diagnosis and treatment of inflammation of the distal hock. Proc. Conv. Amer. Ass. Eq. Pract., 1983, 28, 287-298.

Hartung K, Munzer B, Keller H: Radiologic evaluation of spavin in young trotters. Veterinary Radiology. 1983, 24, 153-155.

Hugason K: Breeding of Iclandic toelter horses: an overview. Livestock Production Science 1994, 40, 21-29.

Lindberg $S$ : Personal communication 1998. Svenska Islandshästföreningen, Box 167, 44824 Floda, Sweden.

$O$ 'Brien TR: Radiographic interpretation of the equine tarsus. Proceedings of the nineteenth annual convention of the American Association of Equine Practitioners. 1974, 289-300.

Odenhall T: Personal communication. Försäkringsaktiebolaget Agria (Agria Insurance), Stockholm, Sweden. 1996.

Rooney JR: Biomechanics of equine lameness. Cornell Vet. 1968, 58, 49-58.

SAS Institute Inc.: JMP 3.2, Cary, NC, USA, 1995.

Stashak TS, Kainer RA, Lebel JL, Lewis LD, McIlwraith $C W$, Nixon $A J$, Park RD, Turner $A S$ : Adams' lameness in horses. Lea \& Febiger, Philadelphia. 1987, 694-704.

Todhunter RJ: Pysical Examination. Equine Surgery. WB Saunders Company, Philadelphia. 1992. 866-868.
Watrous B, Hultgren BD, Wagner PC: Osteochondrosis and juvenile spavin in equids. American Journal of Veterinary Research. 1991, 52, 607-612.

Winter D, Bruns E, Glodek P, Hertsch B: Genetic disposition of bone diseases in sport horses. Zuchtungskunde 1996, 68, 92-108.

Asheim $A$, Lindblad $G$ : Intra-Artcular Treatment of arthritis in race-horses with sodium hyaluronate. Acta vet. scand 1976, 17, 379-394.

\section{Sammanfattning \\ Sambandet mellan bakbenshälta och radiologiska tecken på benspatt hos Islandshästar i Sverige.}

Prevalensen av bakbenshälta samt korrelationen mellan bakbenshälta och radiologiska tecken på benspatt undersöktes genom en fältstudie av en population islandshästar i Sverige. Totalt 379 hästar, 238 valacker, 125 ston och 16 hingstar i åldrarna 1-19 år med en medelålder av 8.1 år undersöktes genom palpation av hasens mediala glidledsområde, bedömning av rörelser $i$ trav samt genom högt böjprov av båda bakben. En dorsolateral-plantaromedial röntgenbild togs på varje hasled. Palperbara avvikelser noterades hos $118(31 \%)$ hästar, hälta hos $43(12 \%)$, positiv böjprovsreaktion hos $94(25 \%)$ hästar samt radiologiska tecken på spatt hos $88(23 \%)$ hästar. Det förelåg ett signifikant korrelation mellan palpatoriska förändringar, hälta, böjprovsreaktion och radiologiska tecken på benspatt. Andelen hasleder med radiologiska fynd ökade med graden av palpationsfynd och hältsymtom. Andelen halta ben ökade med tilltagande grad av radiologiska tecken på benspatt. Däremot sågs ingen korrelation mellan andel hästar med palpationsfynd eller positiv böjprovs reaktion och grad av radiologiska förändringar. Med hjälp av palpation, rörelse undersökning och böjprov identifierades $75 \%$ av hästarna med radiologiska tecken på benspatt.

(Received May 21, 1997; accepted April 15, 1998).

Reprints may be obtained from: M. Axelsson, Department of Large Animal Clinical Sciences, Faculty of Veterinary Medicine, SLV, Box 7018, S-750 07 Uppsala, Sweden. E-mail: Mats.Axelsson@kirmed.slu.se, tel: 46-18-67 13 64, fax: 46-18-67 2919. 
